\title{
Calibration of accelerated corrosion protocol for reinforced concrete columns
}

\author{
Aditya Singh Rajput* and Umesh Kumar Sharma \\ Department of Civil Engineering, Indian Institute of Technology, Roorkee 247 667, India
}

Researchers globally have adopted different techniques for simulating the effects of corrosion on reinforced concrete (RC) sections in different experimental studies. Application of Faraday's law remains the most commonly used technique for designing and controlling accelerated corrosion regimes for testing $\mathrm{RC}$ sections. In this study, we analyse the competence of Faraday's law-based methodology to simulate corrosion of RC structures in laboratory conditions. Twelve small-scale $(300 \times 300 \times 500 \mathrm{~mm}) \quad \mathrm{RC}$ columns were subjected to Faraday's law-based accelerated corrosion regime. Variables of the study were the degree of corrosion and grade of concrete. Damage in the RC section due to corrosion was evaluated in terms of surface distress, corrosion cracking, surface strain and gravimetric examination. Monitoring of the corrosion process through potentiometric measurements and comparing the results with the obtained gravimetric results yielded calibration factors for Faraday's law-based procedure. The proposed calibration factors were then validated by designing and testing accelerated corrosion for large-scale RC columns.

Keywords: Accelerated corrosion, calibration, Faraday's law, RC members.

CORROSION of reinforcing bars is recognized as one of the primary modes of deterioration in reinforced concrete (RC) structures ${ }^{1-3}$. Anodic action of this electrochemical process causes reduction in the cross-section of the rebar resulting in its inferior mechanical behaviour. This reduction in cross-section may be pitting or uniform in nature, and primarily depends on the exposure type (chloride attack or carbonation $)^{4}$. Another manifestation of corrosion in RC members is distress in concrete identified by cracking and delamination or spalling of cover concrete ${ }^{5}$. Cracking and delamination of concrete cover in corroded $\mathrm{RC}$ members take place due to the expansive nature of oxidation products formed as a by-product of the corrosion process ${ }^{6-8}$. Corrosion of steel in RC structures is an electrochemical phenomenon involving the flow of electrons coupled with chemical reactions. The passivation against corrosion provided to the reinforcing bar by alkaline concrete is attacked in aggressive environments such

\footnotetext{
*For correspondence. (e-mail: adirajcivil@gmail.com)
}

as chlorination or carbonation. This stage of the end of passivation is termed as the initiation stage of corrosion, and depends on various material and environmental factors. This stage is then followed by damage and propagations ${ }^{9}$, resulting in cracking and spalling of concrete cover in RC members.

Under natural conditions, the progression of these corrosion stages may expand to several years. Therefore, achieving real-field corrosion in the laboratory within a reasonable time has been an arduous but obligatory task for researchers. In order to accelerate corrosion in the laboratory, impressed current technique has emerged as one of the effective approaches. This technique involves application of external direct current (DC) to the exposed $\mathrm{RC}$ specimen under corrosion favourable environment. This accelerated regime uses Faraday's law as the fundamental equation for determining the corrosion rate of metals in terms of weight loss per ampere of current flow per unit time. Different studies in the experimental context have adopted Faraday's law-based methodology for accelerated corrosion regimes ${ }^{10-13}$. Though validity and rationality of this methodology for simulating real-field corrosion have been confirmed by previous studies ${ }^{14,15}$, the amount of charge $(Q)$ required to achieve targeted corrosion remains undetermined ${ }^{16}$. Equation (1) presents the basic formulation of Faraday's law. It should be noted that the current form of Faraday's law considers the reaction $\mathrm{Fe} \rightarrow \mathrm{Fe}^{2+}+2 e^{-}$to consume all the provided equivalents. However, due to the presence of concrete, other competing reactions also consume the provided equivalents and hence do not contribute to the effective anodic reaction. This results in reduced efficiency of Faraday's law for predicting the actual mass loss in the provided electric charge given in eq. (1).

$$
\begin{aligned}
& Q_{\text {provided }}=\frac{m_{\text {loss }(t)} M_{\text {specimen }}}{n_{\text {specimen }} C_{\text {Faraday }}}, \\
& Q=\int_{t=0}^{t=t} A \mathrm{~d} t .
\end{aligned}
$$

In order to achieve targeted mass loss, it is essential to evaluate the calibration factor using trial and error technique, as explained below in eqs (3)-(5). In order to reduce the number of trial specimens, an initial value of 
calibration factor $\alpha$ was assumed based on knowledge from the literature ${ }^{17}$. After completion of exposure according to the modified charge based on assumed calibration factor, the achieved mass loss was found using gravimetric method. The ratio of theoretical mass loss and achieved mass loss was calculated as $\alpha$, and termed as the calibration factor. Based on the obtained calibration factor $(\alpha)$, eq. (1) can be modified as eq. (5). This factor was utilized for the subsequent specimen, and the process was repeated until the gravimetric mass loss was achieved within satisfactory limits $( \pm 1 \%)$ of targeted mass loss.

$$
\begin{aligned}
& Q_{\text {effective }}=\frac{m_{\operatorname{loss}(g)} M_{\text {specimen }}}{n_{\text {specimen }} C_{\text {Faraday }}}, \\
& \alpha=\frac{Q_{\text {provided }}}{Q_{\text {effective }}}=\frac{m_{\operatorname{loss}(t)}}{m_{\operatorname{loss}(g)}} \\
& Q_{\text {provided }}=\alpha \times \frac{m_{\text {loss }(t)} M_{\text {specimen }}}{n_{\text {specimen }} C_{\text {Faraday }}},
\end{aligned}
$$

where $Q$ is the electric charge provided, $t$ the time (sec), $A$ the DC current (A), $m_{\operatorname{loss}(t)}$ the theoretical mass loss, $m_{\text {loss }(g)}$ the achieved gravimetric mass loss required $(\mathrm{g})$, $M_{\text {specimen }}$ the molar mass of the reinforcement bar (55.8 mol), $n_{\text {specimen }}$ the valency equal 2, C $\mathrm{C}_{\text {Faraday }}$ Faraday's constant $(96,485 \mathrm{C} / \mathrm{mol})$, and $\alpha$ is the proposed calibration factor for Faraday's law.

\section{Significance of the study}

The efficiency of Faraday's law-based accelerated corrosion regime is greatly influenced by different material and environmental parameters. To address this, it becomes important to calibrate Faraday's law for different combinations. The present study calibrates Faraday's law for some important combinations, including corrosion degree and concrete grades. Additionally, the morphological observation of corrosion over RC element yields some critical outcomes. Results of the study helped in predicting the exact amount of charge for achieving targeted corrosion in case of large-scale specimens representing real site conditions.

\section{Experimental procedure}

\section{Specimen preparation}

Twelve square RC prisms were designed and tested under this programme. The test specimens were so designed to represent section and reinforcement detailing of largescale RC columns according to the guidelines of IS-13920:1993 (ref. 18) and IS-456:2000 (ref. 19). These specimens had $300 \mathrm{~mm}$ square cross-section and $500 \mathrm{~mm}$ height (Figure 1). Two different grades of concrete, i.e. M30 and M60 were employed for fabrication of column specimens. The reinforcing bars (Tata Tiscon 500D) with composition $0.25 \%$ carbon, $0.035 \%$ sulphur and $0.035 \%$ phosphorus were used as reinforcement. Indian Standard IS-10262:2009 (ref. 20) guidelines were followed for preparing mix design for different concrete grades. While longitudinal reinforcement had $16 \mathrm{~mm}$ diameter bars, the lateral ties were of $10 \mathrm{~mm}$ diameter. Two types of tie arrangement were selected to prepare the cages of prisms simulating large-scale confined concrete columns. These configurations were chosen deliberately to examine the role of location of ties in the sectional loss due to corrosion. All the longitudinal bars, stirrups and ties were numbered and weighed before the preparation of cages. This was done to enable the gravimetric evaluation of corroded bars. A clear cover of $40 \mathrm{~mm}$ was maintained to the reinforcement according to the standard requirement. Concrete was prepared using a rotating drum mixture, and proper compaction of concrete was ensured using needle vibrator. Three companion standard cubes $\left(150 \mathrm{~mm}^{3}\right)$ and three standard-size cylinders $(\phi 100 \mathrm{~mm})$ were cast with each test specimen. These cubes and cylinders were tested to obtain the compressive strength after 28 days.

\section{Corrosion set-up}

The specimens were cured for 28 days and then a grid of brass disks was pasted (using adhesive) on all the four faces of the specimens in order to capture the surface strains in circumferential, diagonal and longitudinal direction (Figure 1). The brass disks were specially designed to facilitate the jaw of a digital Vernier calipers to fit in, that allowed taking readings up to the maximum accuracy of $0.01 \mathrm{~mm}$. The readings between the disks were measured using the digital Vernier calipers in circumferential, longitudinal and diagonal directions
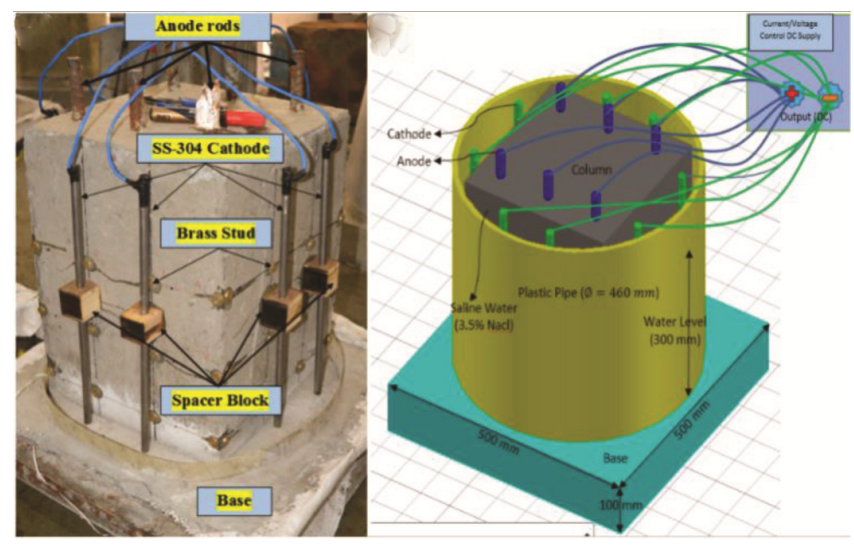

Figure 1. Preparation of specimens for corrosion exposure. 


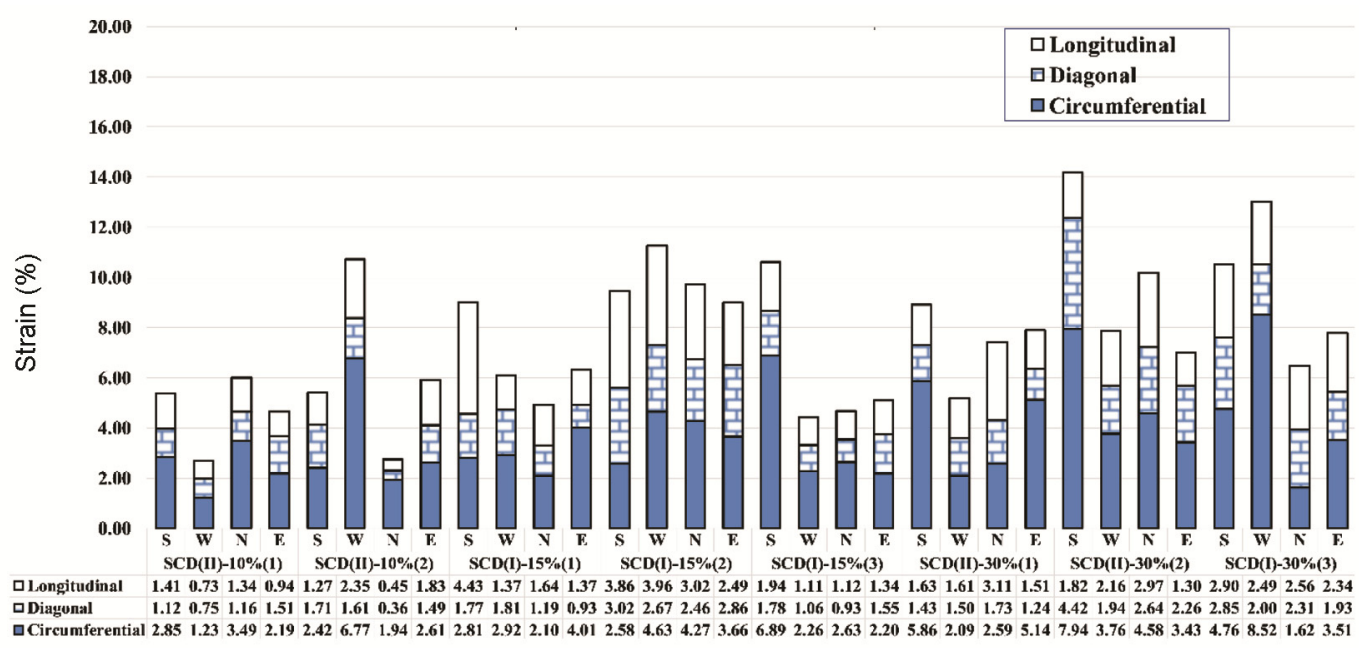

Figure 2. Relative surface strain in longitudinal, diagonal and circumferential directions.

before and after exposing the specimens to corrosion. The measured readings allowed us to quantify the amount of strain suffered by the cover surface due to corrosioninduced expansive stresses. Similar methodology for surface strains has been reported in the previous study by Tamer and Khaled ${ }^{14}$.

Columns were embedded into the concrete base of $100 \mathrm{~mm}$ height and $500 \mathrm{~mm}$ square shape. A plastic pipe was inserted in the fresh concrete base around the specimens just after casting. This pipe was installed to facilitate the presence of saline water around the specimens. The saline water was prepared by mixing 3.5\% salt in normal tap water, which was then poured in the annular space between the specimen surface and surrounding pipe (Figure 1). A specially designed DC supply (current control) of $30 \mathrm{~A}$ and $100 \mathrm{~V}$ capacity was used for applying impressed current. Spacer blocks (wooden) were prepared and attached on the surface of the specimens to maintain a constant distance of cathode rods from the specimen surface. Solid stainless-steel bars of $10 \mathrm{~mm}$ diameter were used as cathode.

After 28 days of curing, the columns were allowed to mature for another month (30 days) before starting corrosion exposure. Corrosion current density of $200 \mu \mathrm{A} / \mathrm{cm}^{2}$ was applied in all the cases. Direct voltage and DC in specimens were recorded after every $24 \mathrm{~h}$ interval in order to monitor variation in resistance. The total duration of the required exposure to achieve target corrosion was calculated using Faraday's law with assumed initial calibration coefficients based on the literature.

\section{Results and discussion}

\section{Surface strain}

Brass disks were pasted on all the four faces of the specimens in a grid-like pattern before corrosion expo- sure. Distances in longitudinal, diagonal and circumferential directions between disks were measured with the help of mechanical strain gauges before and after corrosion. They were then used to compute strains in a particular direction. Strain over the surface of the RC element is primarily influenced by the rate of corrosion, if the rate of corrosion is higher, the corrosion strains will be higher ${ }^{15}$. Strain in the circumferential direction signifies corrosion in longitudinal reinforcement and strain in the longitudinal direction indicates corrosion in transverse reinforcement. Figure 2 shows that strains in the circumferential direction are higher than in the other two directions. This was corroborated by the fact that the cracking in the longitudinal direction was more prominent. Similar observations of longitudinal cracking have been reported in the literature $^{21}$. Besides the build-up of circumferential strains more prominently signifying the corrosion of main bars, enough strain built up along longitudinal and diagonal directions in the present study. This shows that the lateral ties also undergo significant corrosion in addition to corrosion of the main bars. Further, the amount of strain was different on the various faces of the test specimens. This difference represents the asymmetry in the resistance offered by cover concrete resulting in different rates of corrosion on different faces. It may also be concluded that circumferential strains are almost equal to the summation of the strains in the other two directions (longitudinal and circumferential). Observations from gravimetric examination implicitly indicated a higher mass loss in the stirrups than in the longitudinal bars. Hence one may argue that the longitudinal strains should be higher than those in the circumferential direction. However, it should be noted that the deposition of corrosion by-products may not necessarily occur in the vicinity of anodes $^{22}$. The deposition of corrosion by-products is highly influenced by the corrosion current density, location of the cathode and charge present in the circuit. 
Since the DC was supplied through longitudinal bars, it might have promoted higher deposition around these bars, resulting in higher circumferential strains.

The magnitude of strains was greater in specimens exposed to a higher degree of corrosion, though the distribution of strains changed. Average strains for the $10 \%$ corrosion category specimens were $2.92 \%, 1.27 \%$ and $1.64 \%$ in circumferential, diagonal and longitudinal directions respectively. For specimens subjected to $15 \%$ corrosion, the strains were $3.41 \%, 1.84 \%$ and $2.3 \%$ in circumferential, diagonal and longitudinal directions respectively. In $30 \%$ corrosion category specimens, the strains for circumferential, diagonal and longitudinal directions were $4.48 \%, 2.19 \%$ and $2.3 \%$ respectively. It should be noted that at a lower degree of corrosion, the rate of increase in longitudinal strains is higher, which signifies relatively higher corrosion in transverse reinforcement in the initial stages of corrosion. Whereas, at a higher degree of corrosion, the increment in longitudinal strains became gradual (Figure 3). The reduction in corrosion contribution may be understood by the occurrence of snapping of lateral stirrups at higher corrosion degree, which was evident in the broken corroded cage. Figure 4 depicts typical visuals of corroded cage corresponding to

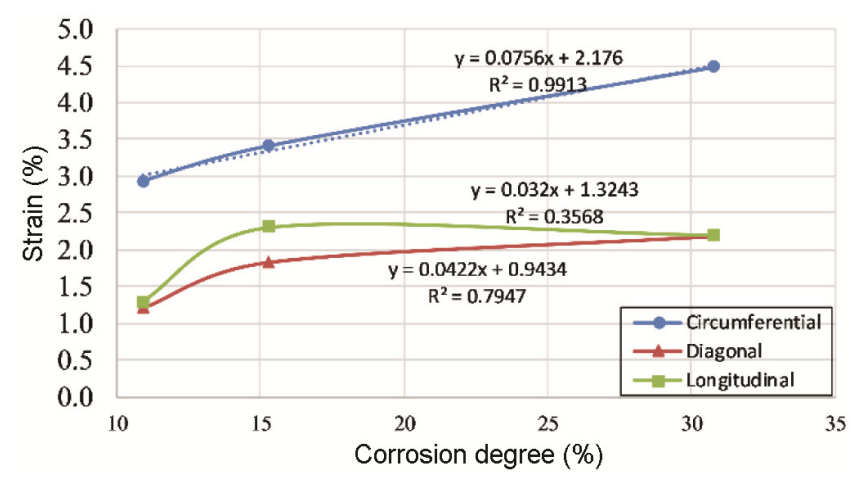

Figure 3. Variation of strain with increasing corrosion degree.

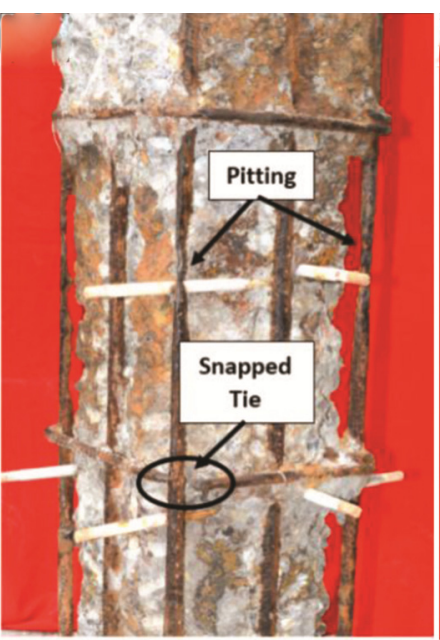

$15 \%$ Corossion degree

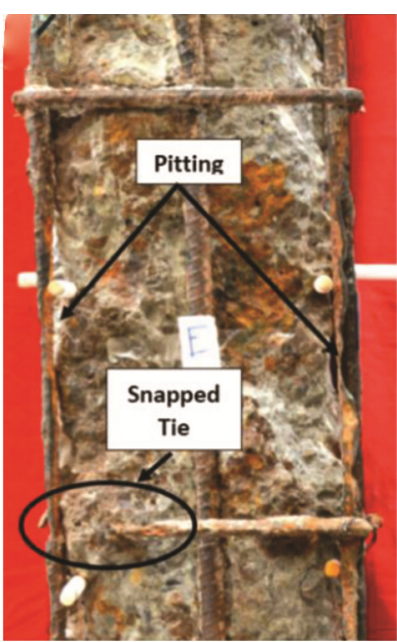

$30 \%$ Corossion degree
Figure 4. Typical appearance of demolished specimen.
$15 \%$ and $30 \%$ corrosion degree. It may be noted from Figure 4 that even at $15 \%$ corrosion degree, snapping of the stirrups took place, resulting in significant loss to the confinement efficiency. This loss in the stirrups increased with corrosion degree. Thus one may conclude that significant deterioration of transverse reinforcement/special confining reinforcement even at lower corrosion degrees shall significantly affect the seismic behaviour of $\mathrm{RC}$ structures.

\section{Observations on cracking}

After completion of exposure, specimens were taken out of the set-up and corrosion products were collected from the surface. After collection of the corrosion products, the specimens were cleaned properly and observed for surface cracks. At the same time, the surface strains, as reported in the previous section, were also noted. A crack scope with the least count of $0.02 \mathrm{~mm}$ was used to measure crack width. The cracks were highlighted further by marking them for improved visibility. A typical crack pattern in terms of crack width and orientation is shown in Figure 5 for specimen SCD(II)-10\%(1). Though the primary direction of cracking was longitudinal, the crack pattern observations revealed that the direction of crack was significantly tilted in a diagonal direction as well. This observation of diagonal cracking is contrary to most of the previous studies reporting cracks primarily in the longitudinal direction ${ }^{17}$, but in line with the observations reported by Ma et al. ${ }^{23}$. It should be noted that the direction of corrosion cracks primarily depends on the component of the reinforcing cage being corroded. Some studies have examined the effects of corrosion of only transverse reinforcement ${ }^{24}$, and some others have considered corrosion of only longitudinal reinforcement ${ }^{17}$. As a result, the

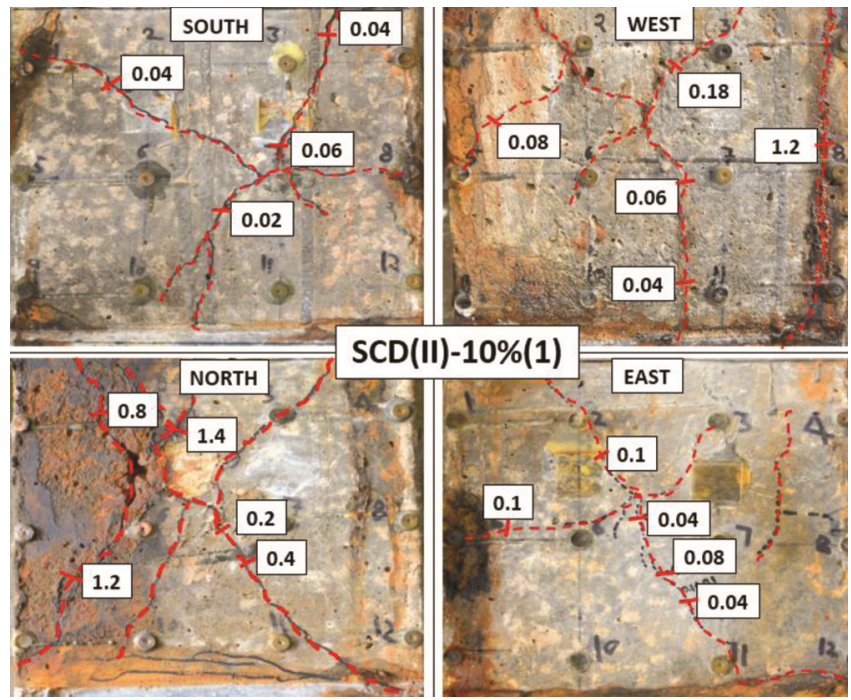

Figure 5. Corrosion cracking on the specimen surface. 
Table 1. Summary of corrosion achieved

\begin{tabular}{|c|c|c|c|c|c|}
\hline \multirow[b]{2}{*}{$\begin{array}{l}\text { Specimen } \\
\text { (ID) }\end{array}$} & \multirow[b]{2}{*}{$\begin{array}{c}\text { Calibration } \\
\text { factor }(\alpha)\end{array}$} & \multicolumn{4}{|c|}{ Percentage mass loss } \\
\hline & & $\begin{array}{c}\text { Average } \\
(\%)\end{array}$ & $\begin{array}{l}\text { Longitudinal } \\
\text { bar }(\%)\end{array}$ & $\begin{array}{l}\text { Peripheral } \\
\text { tie }(\%)\end{array}$ & $\begin{array}{c}\text { Cross/diamond } \\
\text { tie }(\%)\end{array}$ \\
\hline $\operatorname{SCD}(\mathrm{II})-10 \%(1)$ & 1.25 & 11.09 & 7.04 & 22.13 & 4.1 \\
\hline SCD(II)-10\%(2) & $1.2 *$ & 10.74 & 6.75 & 21.23 & 4.23 \\
\hline $\operatorname{SCD}(\mathrm{I})-15 \%(1)$ & 1.6 & 17.50 & 13.29 & 27.92 & 11.29 \\
\hline $\operatorname{SCD}(\mathrm{I})-15 \%(2)$ & 1.4 & 13.41 & 9.05 & 24.45 & 6.73 \\
\hline $\operatorname{SCD}(\mathrm{I})-15 \%(3)$ & $1.5^{*}$ & 14.97 & 12.03 & 24.64 & 8.26 \\
\hline $\operatorname{SCD}(\mathrm{II})-30 \%(1)$ & 2.1 & 31.83 & 30.46 & 53.84 & 11.18 \\
\hline SCD(II)-30\%(2) & 2 & 31.95 & 24.28 & 64.78 & 6.78 \\
\hline $\operatorname{SCD}(\mathrm{I})-30 \%(3)$ & $1.9^{*}$ & 29.85 & 27.3 & 52.3 & 27.3 \\
\hline $\operatorname{HSCD}(\mathrm{I})-10 \%(1)$ & $1.4^{*}$ & 10.58 & 7.47 & 20.31 & 3.97 \\
\hline $\operatorname{HSCD}(\mathrm{II})-15 \%(1)$ & 1.9 & 16.81 & 11.23 & 35.48 & 3.73 \\
\hline $\operatorname{HSCD}(\mathrm{I})-15 \%(2)$ & 1.8 & 15.93 & 12.45 & 30.94 & 4.40 \\
\hline $\operatorname{HSCD}(\mathrm{II})-15 \%(3)$ & $1.7^{*}$ & 14.47 & 12.36 & 28.42 & 2.03 \\
\hline \multicolumn{6}{|l|}{ Large-scale column } \\
\hline $\mathrm{FCD}(\mathrm{II})-10 \%$ & 1.2 & 10.01 & 9.68 & 15.78 & 4.5 \\
\hline FCD(II)-15\% & 1.52 & 14.86 & 14.49 & 24.63 & 5.45 \\
\hline FCD(II)-30\% & 1.95 & 29.76 & 44.94 & 30.36 & 13.97 \\
\hline HFCD(II)-15\% & 1.71 & 15.32 & 14.49 & 27.02 & 4.46 \\
\hline
\end{tabular}

* Marked values are the finalized calibration factor of a particular category. The rate of mass loss and current density for all the specimens were kept constant, i.e. $1.2 \mathrm{~g} / \mathrm{h}$ and $200 \mu \mathrm{A} / \mathrm{cm}^{2}$ respectively.

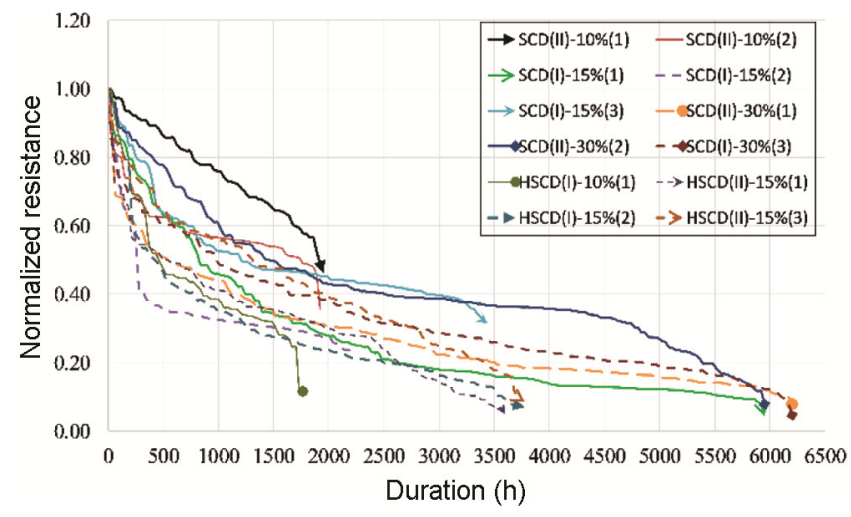

Figure 6. Resistance variation with time.

cracking reported in these studies was either in transverse or longitudinal directions only. The present study allowed corrosion of both longitudinal and lateral steel simultaneously, resulting in the appearance of diagonal cracks owing to significant amount of corrosion in both transverse as well as longitudinal directions causing internal stresses in the circumferential direction.

\section{Calibration of accelerated corrosion protocol}

As stated earlier, the primary aim of this study was to examine the efficiency of Faraday's law in designing accelerated corrosion protocols. All the components of the reinforcement cage, i.e. longitudinal bars, peripheral tie and diamond/cross ties were weighed and numbered before the preparation of the cage. Potentiometric readings such as flowing current and available voltage were measured, and variation in resistance was monitored (Figure 6).

Specimens subjected to corrosion were demolished after achieving the calculated amount of charge. Reinforcement bars were then cleaned with chemical and mechanical methods according to the guidelines of $\mathrm{ASTM}^{25}$. After cleaning, the weight of each component of longitudinal bars and stirrups was recorded, and loss in weight was calculated. This loss in weight was reported as the degree of corrosion.

The duration of corrosion exposure for certain target corrosion of the specimens was calculated with the help of modified Faraday's law according to eq. (5). Initially, a calibration factor $\alpha$ of 1.25 was selected for M30-grade specimens corresponding to $10 \%$ corrosion (Table 1). After achieving the calculated charge for the chosen specimen SCD(II)-10\%(1) of this category, the corrosion was stopped which was followed by visual inspection, demolition and cleaning of reinforcement. The weight loss was recorded for each component (Table 1). The average mass loss of the entire reinforcement cage was reported as corrosion degree. This degree of corrosion was compared with the target degree of corrosion and calibration factor was modified accordingly for subsequent test specimens. For specimen SCD(II)-10\%(1), a degree of corrosion of $11.09 \%$ was achieved in place of target degree of $10 \%$. Hence the chosen calibration factor was reduced to 1.2 for the next specimen, i.e. SCD(II)$10 \%(2)$. The same procedure was repeated for specimen 
$\operatorname{SCD}(\mathrm{II})-10 \%(2)$ with the modified $\alpha$-value (1.2). As a result, the achieved degree of corrosion for this specimen was $10.74 \%$, which was well within the tolerance limit of $\pm 1 \%$. Therefore, for M30 concrete-grade specimens targeting $10 \%$ corrosion degree, a calibration factor $(\alpha)$ of 1.2 was finalized. Corrosion for a specimen with targeted $15 \%$ corrosion degree was started with the initially assumed $\alpha=1.6$. A similar procedure was followed for this category as well, and the finalized calibration factor was achieved as $\alpha=1.5$. In case of specimens made with M30-grade of concrete with 30\% targeted corrosion degree, an initial calibration factor of 2.1 was used. Totally three specimens were corroded in this category and the finalized calibration factor achieved in the last specimen was $\alpha=1.9$. This calibration factor resulted in achieving a corrosion degree of $29.85 \%$. This degree of corrosion value was accepted as it was close to the required value of $30 \%$, and calibration factor of 1.9 was thus finalized for this category of specimen.

Once the calibration factors were finalized for the concrete grade of M30, a similar procedure was used for evaluating calibration factors for specimens of M60 grade of concrete for various targeted degrees of corrosion. Targeted corrosion degrees for this grade of concrete were $10 \%$ and $15 \%$, and a total of four specimens were employed. It should be noted that the higher grade concrete offers higher resistance against corrosion and hence, the efficiency of Faraday's law in higher-grade concrete gets further compromised. Similar observations have been reported in the literature ${ }^{26}$. This is the reason for the selection of a higher calibration factor for this grade. Specimens HSCD(I)-10\%(1) was corroded taking $\alpha=1.4$ into account and exposure till modified charge was provided. The obtained results of gravimetric examination revealed the corrosion degree to be $10.58 \%$ which was satisfactorily within the tolerance limit of $\pm 1 \%$. This value of calibration factor $\alpha=1.4$ was finalized for this category. The next and last category for calibration regime was M-60-grade concrete with $15 \%$ corrosion degree. To accommodate the lower efficiency of Faraday's law in higher-grade concrete case, we selected initial $\alpha=1.9$. Specimen $\operatorname{HSCD}(\mathrm{II})-15 \%$ (1) was corroded under the corrosion regime of $\alpha=1.9$, while keeping all other variables the same. The corrosion degree achieved after this corrosion regime was $16.81 \%$, which was significantly higher than the desired $15 \%$ level. Due to this higher corrosion level achieved, the calibration factor for subsequent specimen $\mathrm{HSCD}(\mathrm{I})-15 \%(2)$ was reduced to 1.8 from 1.9 and further reduced to 1.7 from 1.8 for subsequent specimen $\operatorname{HSCD}(\mathrm{II})-15 \%(3)$. The corrosion degree achieved through this calibration factor $(\alpha=1.7)$ was $14.47 \%$; since this achieved value was within the reasonable limit, this calibration coefficient ( $\alpha=1.7$ ) was finalized.

The preceding discussion indicates the drawbacks of direct application of Faraday's law in designing and implementing accelerated corrosion protocols for RC sections. The present study enabled evaluating the efficiency of Faraday's law corresponding to various degrees of corrosion. The efficiency of Faraday's law for simulating corrosion in case of normal strength concrete was $20 \%$, $50 \%$, and $90 \%$ lower for target degrees of corrosion of $10 \%, 15 \%$ and $30 \%$ respectively. This may be addressed by selecting appropriate calibration or calibration coefficients proposed in the study. The results also show that the efficiency of Faraday's law reduces as the grade of concrete increases, as high calibration factors were obtained for M60-grade than M30-grade of concrete. The reason for this lower efficiency may be due to the fact that higher-grade concrete offers higher resistance to chloride ions to the travel to anodic site and hence delays the corrosion initiation. Further, the anodic site in the corrosion process keeps on shifting depending on the deposition of corrosion by-products (acts like a protective layer) and relative resistance. This process results in increased competitive reaction and reduced effective diffusion of equivalents. A similar observation has been reported in the literature ${ }^{26}$, where higher strength concrete resulted in lowering the amount of corrosion at similar electric charge.

\section{Application of calibration methodology over large-scale columns}

Several studies on the durability aspects of large-scale $\mathrm{RC}$ specimens have been conducted in recent years. In order to examine the size effects and thereby ascertain the accuracy of the developed calibration factors, large-scale columns were also cast and exposed to corrosion regimes. Four column specimens, each of height $1800 \mathrm{~mm}$ and cross-section $300 \times 300 \mathrm{~mm}$, were constructed along with a stub of size $1000 \times 600 \times 550 \mathrm{~mm}^{3}$ (Figure 7). The bottom $800 \mathrm{~mm}$ of column portion was chosen as the test length and was exposed to corrosion. Before preparation of the reinforcement cage, the stirrups and ties in the test length region were weighed and numbered. This was done to evaluate the mass loss after corrosion exposure. After weighing and numbering of the stirrups, the cage for columns and footing-stub was prepared. Before casting, the vertical alignment of the mould was ensured, and sealing was done to avoid any leakage of slurry while casting or vibrating. Rotating drum mixture and needle vibrator were used for casting of the specimens, while the concrete mix proportions were designed according to the current Indian guidelines ${ }^{20}$. Six companion cubes and cylinders were cast with the column specimens.

After curing of the column specimens, they were prepared for accelerated corrosion experiments. The column specimens were wrapped in the upper $1000 \mathrm{~mm}$ length using GFRP laminate (Figure 7). It was done to avoid corrosion of this portion. After curing of GFRP (48 h), a 


\section{RESEARCH ARTICLES}

circular groove was cut in the base around the column in a diameter of approximately $500 \mathrm{~mm}$ and a hollow pipe was inserted into the groove, and epoxy resin was used for adhesion. This arrangement of hollow plastic pipe was made to facilitate the availability of saline water around the test length of the column. Stainless-steel cathode rods were attached over the column surface, and saline solution with $3.5 \% \mathrm{NaCl}$ was poured up to the height of $700 \mathrm{~mm}$. Subsequently, the specimens were connected to a current-controlled DC supply, and a current density of $200 \mu \mathrm{A} / \mathrm{cm}^{2}$ was maintained for the entire corrosion regime. The columns were exposed to the target corrosion after applying the calibration factors developed on the small-scale specimens. The duration of corrosion exposure for each specimen was decided based on Faraday's law and was primarily a function of the degree of corrosion (mass loss required).

Normal strength (M30) concrete specimen FCD(II)$10 \%$ was exposed to a target degree of corrosion of $10 \%$ using a calibration factor of 1.2. The specimen, after achieving the calculated charge, was demolished in test length portion and bars were extracted and cleaned for gravimetric examination. Actual corrosion of $10.01 \%$ was noted in this specimen, which was quite close to the desired value of $10 \%$. The next specimen $\mathrm{FCD}(\mathrm{II})-15 \%$ meant for target corrosion of $15 \%$ was also studied in the same way and the actual degree of corrosion of $14.86 \%$ was achieved, which was again satisfactory and within the tolerance limit of $\pm 1 \%$. The next specimen, viz. specimen $\mathrm{FCD}(\mathrm{II})-30 \%$, was also made up of normal

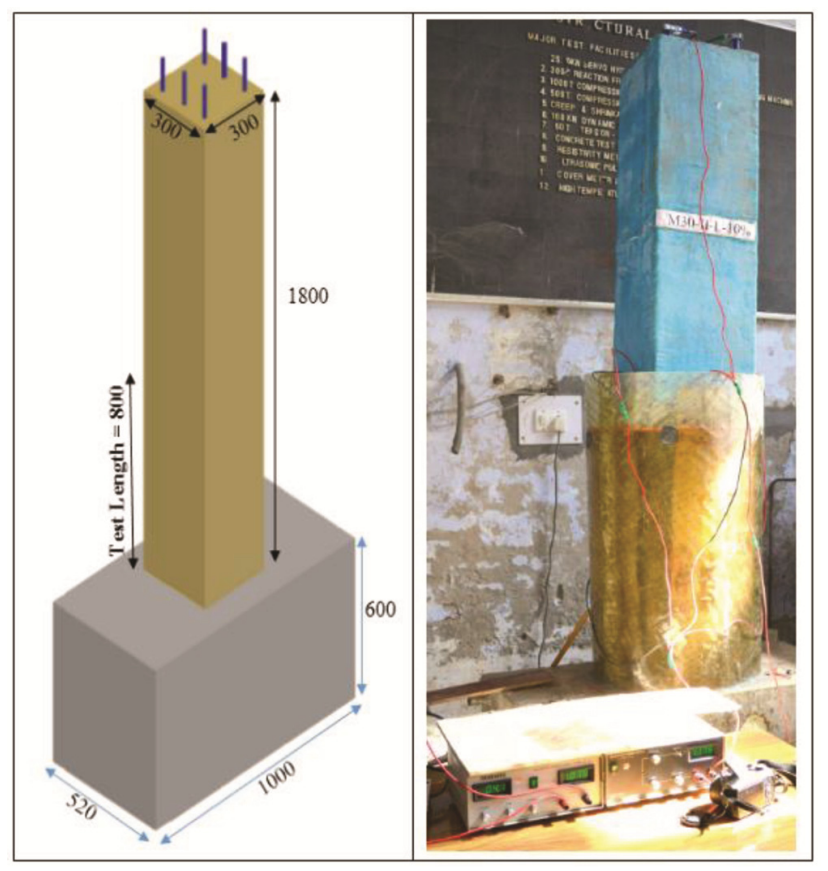

Figure 7. Reinforcement and dimensional details of full-scale column. concrete and was targeting 30\% corrosion degree. Calibration parameter for this specimen was $\alpha=1.9$; the rest of the parameters were kept constant. The obtained corrosion degree for this category was $29.76 \%$, which was again in the satisfactory range of $\pm 1 \%$. The last specimen (HFCD(II)-15\%) was a high-strength concrete specimen with target corrosion degree being $15 \%$. It was corroded taking $\alpha=1.7$. The degree of corrosion for this specimen was $15.32 \%$ which was well within the satisfactory limits and hence accepted. The above results show the significance of undertaking a pre-calibration of Faraday's law before exposing the large-scale RC specimens to some target corrosion levels.

\section{Gravimetric examination}

The condition of corroded reinforcement after demolition of concrete was examined while carrying out gravimetric studies. As expected, the two components of the reinforcement cage, namely longitudinal reinforcement and transverse reinforcement suffered damage due to corrosion exposure to different levels. The reason behind this is evidently the placement of these reinforcement components with respect to the external surfaces. The peripheral ties are situated closer to the exterior surface and are thus always the first ones to be attacked by corrosion exposure. Furthermore, existing surface micro-cracks on the bent portion of the stirrups make them even more vulnerable to corrosion. The degree of corrosion reported in most of the previous studies was the average mass loss of the entire corroded reinforcement cage, and particular emphasis over component-wise loss was not reported. However, in the present study we determine the degree of corrosion based on either longitudinal or transverse steel. Figure 8 shows the outcome of the gravimetric examination in terms of loss in longitudinal and transverse reinforcement components separately for various degrees of corrosion. Each specimen has been illustrated in terms of four values. The first bar from the left shows mass loss of the longitudinal bars; the second bar shows mass loss of peripheral hoop/tie, the third bar shows corrosion degree of cross-tie or diamond tie and the overlapping fourth bar (central) shows the average of all the three. Note that this average value was taken as the degree of corrosion for a given case in the preceding discussion. Values at the top of each bar depicts the respective corrosion degree, while the bold numbers on top of each set of data show the calibration factor used in that particular specimen.

It is evident from Figure 8 that for all the specimens, the average mass loss in the peripheral ties was significantly higher than that of the entire reinforcement cage, except in specimen $\mathrm{FCD}(\mathrm{II})-30 \%$. This may be due to the presence of local honeycombing, which might have resulted in the concentration of corrosion in one location 
RESEARCH ARTICLES

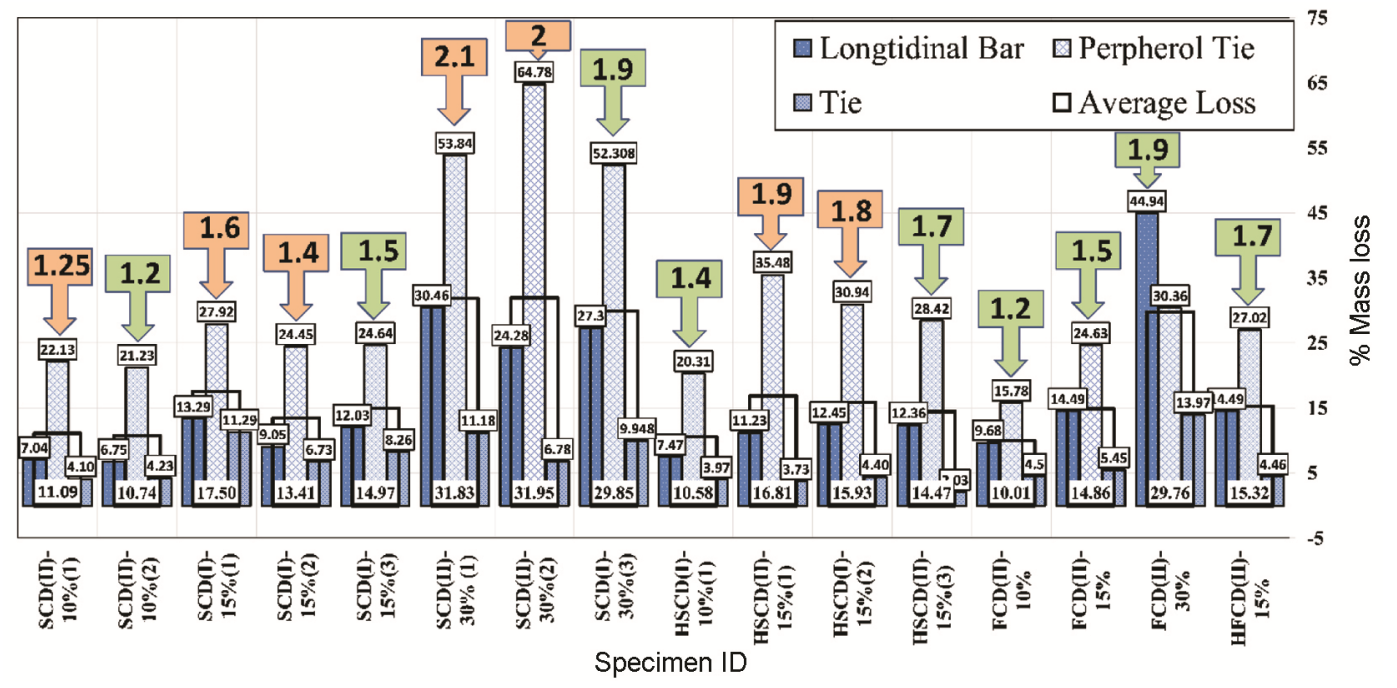

Figure 8. Component-wise loss of reinforcement and corresponding calibration factors.

and heavy loss of the longitudinal bars. Thus this result may be taken as an experimental anomaly. In all other specimens, mass loss in the peripheral ties was almost double the average mass loss of the entire cage system. The mass loss of peripheral tie ranged between $157 \%$ and $211 \%$, while the average mass loss of the peripheral tie was $183 \%$. This indicates that the peripheral ties experience considerably more loss in cross-section due to corrosion, which further shows that confining action and shear strength provided by transverse outer ties would be significantly compromised even at low degrees of corrosion. Furthermore, it was observed during visual inspections that some of the peripheral ties even got completely disconnected at a few locations. The disconnected ties will result in zero contribution towards confinement and shear strength.

The longitudinal bars experienced mass loss ranging between $63 \%$ and $98 \%$ with an average value of $80 \%$. The least affected component of the cage was cross ties or diamond ties (Figure 8). This shows that provision of cross-ties and diamond ties, which would be relatively less affected by corrosion, should be relied more upon for providing transverse confinement compared to peripheral ties. For a typical corrosion scenario, ductility of a confined column with diamond ties will be less affected than ductility of a column with peripheral ties.

\section{Summary and conclusion}

Twelve small-scale RC prisms were corroded in an accelerated corrosion regime to calibrate Faraday's law and to understand the effects of corrosion on reinforcing bars of different configurations. The following conclusions may be drawn from the present study:

(1) The efficiency of Faraday's law is compromised in the presence of concrete, and a well-designed calibration may be useful in achieving target corrosion in a given reinforced concrete corrosion experiment.

(2) The study shows that the efficiency of Faraday's law reduces for higher corrosion degree and higher concrete grade.

(3) Circumferential strain and longitudinal cracking are more prominent than longitudinal strain and transverse cracking in the RC members, which is in line with the previously reported results. However, this study shows that in well-confined concrete sections, corrosion of transverse reinforcement alters the direction of strain and resulting cracking.

(4) The results show that peripheral transverse tie is considerably more affected by corrosion than the cross tie, diamond tie and longitudinal bar. This fact should be kept in mind while designing confining and shear reinforcement for the end regions of RC columns, especially in a corrosive environment.

Conflict of interest: The authors declare that they have no conflict of interest.

1. Cabrera, J. G., Deterioration of concrete due to reinforcement steel corrosion. Cem. Concr. Compos., 1996, 18(1), 47-59; doi: 10.1016/0958-9465(95)00043-7.

2. Mondal, G. and Rai, D. C., Performance of harbour structures in Andaman Islands during 2004 Sumatra earthquake. Eng. Struct. 2008, 30(1), 174-182; doi:10.1016/j.engstruct.2007.03.015.

3. Katwan, M. J., Corrosion of steel reinforcement in hot countries, an acute case study. Mater. Struct., 2001, 34, 360-366; doi:10.1007/BF02486487.

4. Wang, X. G., Zhang, W. P., Gu, X. L. and Dai, H. C., Determination of residual cross-sectional areas of corroded bars in reinforced concrete structures using easy-to-measure variables. Constr. Build. Mater., 2013, 38, 846-853; doi:10.1016/j. conbuildmat.2012.09.060.

5. Tapan, M. and Aboutaha, R. S., Effect of steel corrosion and loss of concrete cover on strength of deteriorated RC columns. Constr. 
Build. Mater., 2011, 25(5), 2596-2603; doi:10.1016/j. conbuildmat.2010.12.003.

6. Suda, K., Misra, S. and Motohashi, K., Corrosion products of reinforcing bars embedded in concrete. Corros. Sci., 1993, 35(5-8), 1543-1549; doi:10.1016/0010-938X(93)90382-Q.

7. Careas, S., Nguyen, Q. T., L'Hostis, V. and Berthaud, Y., Mechanical properties of the rust layer induced by impressed current method in reinforced mortar. Cem. Concr. Res., 2008; doi:10.1016/j.cemconres.2008.03.016.

8. Alonso, C., Andrade, C., Rodriguez, J. and Diez, J. M., Factors controlling cracking of concrete affected by reinforcement corrosion. Mater. Struct. Constr., 1998, 31(7), 435-441; doi:10.1007/ BF02480466.

9. Cady, P. D. and Weyers, R. E., Chloride penetration and the deterioration of concrete bridge decks. Proc. Am. Soc. Test Mater., 1983, 2, 81-87.

10. Rodriguez, J., Ortega, L. and Casal, J., Load carrying capacity of concrete structures with corroded reinforcement. Constr. Build. Mater., 1997, 11(4), 239-248; doi:10.1016/S0950-0618(97)00043-3.

11. Capozucca, R., Damage to reinforced concrete due to reinforcement corrosion. Constr. Build. Mater., 1995, 9(5), 295-303.

12. Val, D. V., Deterioration of strength of RC beams due to corrosion and its influence on beam reliability. J. Struct. Eng., 2007, 133(9), 1297-1306; doi:10.1061/(ASCE)0733-9445(2007)133:9(1297).

13. Andrade, C. and Martinez, I., Calibration by gravimetric losses of electrochemical corrosion rate measurement using modulated confinement of the current. Mater. Struct. Constr., 2005, 38(283), 833-841; doi:10.1617/14297.

14. El Maaddawy, T. A. and Soudki, K. A., Effectiveness of impressed current technique to simulate corrosion of steel reinforcement in concrete. J. Mater. Civ. Eng., 2003, 15(1), 41-47; doi:10.1061/(ASCE)0899-1561(2003)15:1(41).

15. Ghanti, R., Effect of Impressed Current on the Microstructure of Corroded Steel-Concrete Interface, Imperial College, London, UK, 2012.

16. Ballim, Y. and Reid, J. C., Reinforcement corrosion and the deflection of RC beams - an experimental critique of current test methods. Cem. Concr. Compos, 2003, 25(6), 625-632; doi:10. 1016/S0958-9465(02)00076-8.
17. Meda, A., Mostosi, S., Rinaldi, Z. and Riva, P., Experimental evaluation of the corrosion influence on the cyclic behaviour of RC columns. Eng. Struct., 2014, 76, 112-123.

18. BIS, IS-13920:1993, Ductile detailing of reinforced concrete structures subjected to seismic forces - code of practice. Bureau of Indian Standard, 2002, 1993 (reaffirmed 1998).

19. BIS, IS 456:2000, Plain and reinforced concrete-code of practice. Bureau of Indian Standard, 2000.

20. IS 10262:2009, Indian Standard for Concrete Mix Proportioning (First Revision), Bureau of Indian Standards, 2009.

21. Xia, J., Jin, W. and Li, L., Performance of corroded reinforced concrete columns under the action of eccentric loads. J. Mater. Civ. Eng. ASCE, 2016, 28(2001), 1-16; doi:10.1061/(ASCE)MT. 1943-5533.0001352.

22. Revie, R. W., Uhlig's Corrosion Handbook, Wiley Sons, 2011, 3rd edn, pp. 1-15.

23. Ma, Y., Che, Y. and Gong, J., Behavior of corrosion damaged circular reinforced concrete columns under cyclic loading. Constr. Build. Mater., 2012, 29, 548-556; doi:10.1016/j.conbuildmat. 2011.11.002.

24. Zhang, G., Cao, X. and Fu, Q., Experimental study on residual strength of concrete confined with corroded stirrups. Can. J. Civ. Eng., 2016, 590, 583-590.

25. ASTM:G1-03 (reapproved: 2011), Standard practice for preparing, cleaning, and evaluating corrosion test. Am. Soc. Test Mater., 2011, 1-9; doi:10.1520/G0001-03R11.2.

26. Abosrra, L., Ashour, A. F. and Youseffi, M., Corrosion of steel reinforcement in concrete of different compressive strengths. Constr. Build. Mater., 2011, 25(10), 3915-3925; doi:10.1016/ j.conbuildmat.2011.04.023.

ACKNOWLEDGEMENT. We thank the Department of Science and Technology, New Delhi for financial support to conduct this study.

Received 29 November 2018; revised accepted 23 September 2019

doi: $10.18520 / \mathrm{cs} / \mathrm{v} 118 / \mathrm{i} 1 / 70-78$ 